\title{
DOSSIER
}

La Ciudad de México, problemas públicos, derechos humanos y participación ciudadana

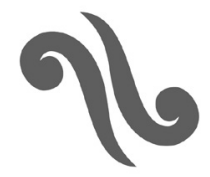





\title{
La Constitución de la Ciudad de México, ciudadanía y participación \\ Continuidades y cambios en la gobernanza urbana
}

\section{The Mexico City Constitution, participation and citizenship Continuity and change in governance processes}

\author{
Arturo Alvarado / Héctor Tejera
}

El artículo examina las transformaciones producidas por la Constitución de la Ciudad de México en la participación ciudadana, mediante un balance del proceso participativo, examinando los efectos de las nuevas reglas en la dinámica política urbana. La pregunta central es si la nueva carta constitucional produjo cambios sustanciales en la participación o, por el contrario, se ha acomodado a procesos sociopolíticos que ya venían ocurriendo; muestra la importancia y los límites de los cambios normativo-constitucionales frente a las complejidades de la acción colectiva en temas urbanos de la mayor metrópolis del centro de México. El artículo combina una reflexión teórica que dialoga con la etnografía, la observación directa, el análisis documental y las entrevistas con actores clave.

Palabras clave: Constitución, Ciudad de México, participación ciudadana, gobernanza, democracia.

The present article analyzes the transformations of Citizens Participation generated by the inception of a new constitution. Asses the consequences of the new rules for the City's political dynamics. The central question of the article is whether or not the constitution has produce a significant change in participatory processes or, on the contrary, just sanctioned sociopolitical processes that were already regulated in old laws; in this senses shows the importance of the new constitutional rules in front of the complexities of collective action in the largest metropolis of Mexico. The articles uses a combination of methods, including ethnography, direct observation, interviews with key actors and extensive documentary analysis.

Key words: Constitution, Mexico City, citizen participation, governance, democracy.

Fecha de recepción: 13 de abril de 2020

Fecha de dictamen: 27 de junio de 2020

Fecha de aprobación: 1 de septiembre de 2020 


\section{INTRODUCCIÓN}

El 2018 marca el inicio de una nueva era política y jurídica de la Ciudad de México (CDMX). Después de una asamblea constituyente de baja intensidad, con una participación ciudadana indiferente, los habitantes de la capital de la nación dejaron atrás el estado de excepción en el que vivieron por más de 80 años, ubicándose en un régimen normativo hipergarantista, en el cual son titulares de numerosos derechos y algunos deberes. ${ }^{1}$ Indudablemente este proceso constitucional implica el cambio jurídico y político más importante de la CDMX por décadas. Es la mayor reforma desde la desaparición de poderes en 1928. La ciudad enmascarada en pasajes de la Constitución de la República y algunos códigos, leyes y estatutos es hoy un ente de gobierno impregnada por la ciudadanización de diversas instituciones de gobierno ${ }^{2} \mathrm{y}$ el impulso a la participación vecinal. Puede sostenerse que se suscita una transición múltiple; para comenzar, de una entidad con ciudadanos y gobernantes acotados se pasa a una entidad con múltiples derechos formales; del autoritarismo posrevolucionario del siglo XX a una democracia limitada; del dominio presidencial sobre la ciudad a la integración de un nuevo poder urbano-estatal; de una entidad sometida a una que marca un nuevo balance de fuerzas entre el Poder Ejecutivo Federal y la capital y, en consecuencia, del equilibrio de poderes dentro del pacto federal.

La participación ciudadana es clave en el desarrollo político de la urbe y de la democracia. Diversos autores han mostrado las formas y mecanismos con los cuales la Ciudad se ha transformado debido a la movilización colectiva (Álvarez, 1997; Sánchez, 2000; Marván, 2012; Tejera y Castro, 2010; Ziccardi,1998). Algunos consideran el papel de las normas y en particular la participación definida como institucionalizada, temática en la cual se concentra una parte sustantiva de la literatura (Alvarado, 2012; Marván, 2012; Sánchez, 2000; Tejera, 2015; Zermeño et al., 2002; Ziccardi, 1998; 2004). Otros la ubican dentro del tema de la gobernanza (Alvarado, 2018; Díaz y Zabaleta, 2018; Le Galès y Ugalde, 2018).

\footnotetext{
${ }^{1}$ En términos cuantitativos encontramos 171 derechos en la Constitución. En la Carta de Derechos se plasman 130; en la sección de Desarrollo Sustentable aparecen 4; en el apartado de Ciudadanía y Ejercicio Democrático hay 15; en la parte correspondiente a los Pueblos y Barrios Originarios y Comunidades Indígenas se incluyeron 21; y, finalmente, en la sección de Responsabilidades de los Servidores Públicos aparece uno más. En cuanto a los deberes tenemos 23 que se condensan en "Deberes de las personas de la Ciudad” en el Título cuarto, capítulo 1, artículo 23.

${ }^{2}$ Por ejemplo, en la mayoría de los organismos autónomos, y en otras instituciones, la elección de titulares e integrantes de su consejo se realizará mediante consejos ciudadanos que se integrarán con ese propósito (véase artículo 46, inciso C).
} 
Ahora bien, en el marco de la nueva Constitución hubo varios debates en torno a sus contenidos y alcances, pero aún hay pocos estudios publicados, y si bien éstos muestran aspectos relevantes del proceso constituyente y sus consecuencias, unos se circunscriben a aspectos jurídicos y rituales muy específicos para el gobierno de la ciudad (Cárdenas, 2016; Yankelevich, 2018), y otros se preguntan cómo se resolverán algunos problemas económicos y sociales (Azuela et al., 2019). Pero no han tomado en cuenta el mutuo impacto entre nuevas reglas para la participación y los procesos mediante los cuales se busca propiciar una ciudad más incluyente, democrática y participativa. Por ello, es pertinente ahondar en las consecuencias de estos cambios tanto para la acción democrática, como para la gobernanza urbana. En este sentido proponemos responder a la cuestión central, sobre si la nueva carta constitucional produce transformaciones sustanciales en la participación o, por el contrario, acomoda la ley a procesos que ya venían ocurriendo. De la misma forma, ¿cuáles son las consecuencias de estas transformaciones para hacer realidad el ejercicio del derecho a la ciudad? Esta pregunta es pertinente porque los reacomodos políticos venían ocurriendo antes de la Constitución. ¿Cómo se adapta el gobierno de la ciudad, a las nuevas reglas? ¿Las acepta e impulsa?, o, por el contrario, ¿continúa con la práctica de crear mecanismos (informales pero consensados) que actúan en las relaciones urbanas paralelos a la Constitución y las leyes para gobernar? Con base en dichas preguntas es posible mostrar la importancia y los límites de los cambios normativo-constitucionales en la Ciudad frente a los procesos urbanos de la mayor metrópoli de México; particularmente, examinando el papel de la participación ciudadana y los efectos de las nuevas normas en procesos que se desarrollan desde hace décadas.

Hacemos un breve recuento del proceso constituyente relacionado con las normas de participación, empezando por la paradoja democrática de haber sido elegido a partir del acotamiento de la participación ciudadana. Además, mostramos que durante el debate no fueron incluidas el grueso de las iniciativas ciudadanas y civiles, no obstante que los constituyentes promovían un discurso del parlamento abierto. Se precisan los cambios sustanciales en materia de participación entre la anterior Ley de Participación Ciudadana (LPC), la Constitución de la CDMX y la nueva LPC. Con base en ella se efectúa un examen sistemático de algunos cambios, omisiones y pendientes en la regulación para, finalmente, presentar dos situaciones contrastantes donde, por un lado, la nueva normatividad se cumple formalmente, ejemplificando con las elecciones de Comités de Participación Ciudadana (CPC) y los ejercicios de "Presupuesto Participativo"; y, por otro lado, analizando sus diferencias con procesos anteriores. 


\section{A. ALVARADO • H. TEJERA LA CONSTITUCIÓN DE LA CIUDAD DE MÉXICO, CIUDADANÍA Y PARTICIPACIÓN}

\section{EL DEBATE SOBRE LAS NORMAS, LA PARTICIPACIÓN Y LA DEMOCRACIA}

Desde un punto de vista teórico la producción de normas es un proceso de construcción institucional que establece o modifica ciertos parámetros de gobierno y genera incentivos y límites para nuevas formas de acción colectiva y de gobierno (Orstrom, 2005). En ocasiones estos procesos permiten una democratización inclusiva y, para ello, la participación ciudadana es estratégica. Al respecto, la democratización de la Ciudad de México es consecuencia de varias décadas de lucha de múltiples actores y movimientos de protesta (partidos, movimientos urbanos vecinales, sindicatos, ONG, actores del gobierno), concertaciones, reformas y creación de acuerdos. De este modo se forjaron instituciones -entre éstas la Asamblea Legislativa-, se establecieron elecciones parciales, y diseñaron reglas de elección y representación para que participaran los habitantes. Durante la transición se fueron fraguando formas de participación e instituciones bajo un régimen no democrático, con una Regencia impuesta por el presidente de la República. Algunas normas creadas durante dicho proceso lograron regular de manera legal y legítima y permitieron canalizar conflictos, disminuyendo el recurso de la transgresión de las normas y el uso de la violencia para instaurar órdenes paralelos.

Algunos textos confirman que dichas formas de participación fueron construyendo, no la ciudadanía idealizada, pero sí la posible en el contexto de las formas de gobierno autoritario que han caracterizado al Estado mexicano, donde los habitantes de la ciudad, mediante sus formas particulares de participar "construyen sus visiones [...] sus ideas de lo que es, no lo que proponen las normas y las teorías" (Tejera y Castro, 2010:13).

\section{LA PARADOJA DEMOCRÁTICA DE LA CONSTITUCIÓN POLÍTICA DE LA CIUDAD DE MÉXICO}

La principal paradoja del proceso constitucional fue la imposición de reglas que impidieron y, en el mejor de los casos, limitaron la participación y la posibilidad de dialogar, debatir e incidir en la manufactura del documento; al extremo de convertir en inútil cualquier propuesta y anular la posibilidad de un proceso de consultas que socializara el proyecto y lo sancionara con la legitimidad ciudadana. Esta es una paradoja mayor dentro de la corriente de izquierda latinoamericana que ha promovido la democracia directa. Además, el contexto político de la nueva Constitución no puede ser más opuesto a formas democráticas participativas impulsadas por la izquierda desde la década de 1980 y, sobre todo, desde el triunfo del Partido de la Revolución Democrática (PRD) en 1997, que desde entonces gobierna la capital; ha sido un periodo de políticas excluyentes que mantienen la segregación, la informalidad y el empleo precario y no resuelven los problemas estructurales de desigualdad, pobreza y exclusión. 
Marván (2012:554) sostiene que la estructura de las formas de participación que emergieron del largo proceso de transición, más que fomentar la participación ciudadana, contribuyeron a dispersarla y en buena medida a pulverizarla; mantiene una tensión entre la representación vecinal y la representación de los partidos políticos (que sería conducente al desarrollo del clientelismo). En sentido similar, Díaz y Zabaleta (2018:61) confirman esta idea de fragmentación y débil articulación de la ciudad, que combina acuerdos formales con informales.

En la siguiente sección hacemos un recuento del desarrollo de categorías, instrumentos y procesos participativos en la Constitución. Luego revisamos cómo se adaptaron los procesos de integración de gobiernos locales y representación vecinal a las nuevas reglas.

\section{PARTICIPACIÓN CIUDADANA Y NUEVA CONSTITUCIÓN}

La Constitución de la Ciudad de México concuerda con la tendencia en América Latina de promover formas de participación ciudadana directa en la formulación y control de las decisiones o políticas públicas (Cunill, 1997; Ziccardi, 1998). Perfila una forma particular de ejercer los derechos (por medio de la participación), propiciando la formación de un horizonte de significación donde los ciudadanos se configuran y juzgan a sí mismos (Foucault, 1991; Murray, 2007). La Constitución expresa el ámbito de los derechos ciudadanos, cómo se desea que se ejerza la ciudadanía y el espacio de relación con el gobierno. Los ordenamientos jurídicos constitucionales o la reglamentación que se haga de éstos pueden modificar el derrotero de las diversas expresiones de la participación. Por ello, los cambios legales introducidos en la Constitución en cuanto a los instrumentos de participación ciudadana y la transformación de las delegaciones en Alcaldías con cabildos abren la posibilidad de evaluar si éstas presentan un cambio sustantivo o mejoría de los procesos participativos, en comparación con los mostrados a lo largo de las tres últimas décadas.

Lo primordial es si la nueva Constitución sanciona lo que ya existía en términos de la participación, o significa un cambio o mejoría de los procesos participativos, tomando en cuenta los siguientes puntos: $a$ ) ¿qué tanto se avanzó en los ordenamientos jurídicos, en comparación con aquellos establecidos, como la las LPC promulgadas en 2006 y 2009; b) ¿̇se profundizó en el contenido democrático de dicha Constitución para impulsar una participación ciudadana con un contenido mejorado?; c) ¡ंcuál es el alcance de la nueva reglamentación en cuanto a la transformación de las delegaciones en alcaldías y qué tanto contribuye a la gobernanza que se pretende alcanzar con ella?; $d$ ) las modificaciones institucionales y la inclusión de nuevos actores sociales ¿̨representan 
una nueva forma de gobernanza o, por el contrario, agregan instituciones y actores a la política local y a la nacional (al Estado) sin condiciones para sustentarla?

En cuanto a la primera y segunda pregunta, puede sostenerse que hay avances y retrocesos en los contenidos de la participación ciudadana. Hay tres etapas de la representación ciudadana formal desde que se realizaron votaciones ciudadanas en 1999. La primera es la elección partidaria de los comités vecinales (CV) caracterizada por la competencia abierta entre los principales partidos: Acción Nacional (PAN), Revolucionario Institucional (PRI) y de la Revolución Democrática (PRD) en 1999. La segunda etapa es la elección gubernamental que inicia con las elecciones de los comités ciudadanos (CC) once años después de esa primera experiencia (en 2010); los cuales son disputados por las diversas fuerzas políticas agrupadas en las diversas facciones del PRD, diputados locales y federales, pero sustancialmente organizadas por las delegaciones políticas con el propósito de que triunfen comités con los que "se pueda trabajar". La tercera, es la elección de dirigentes particulares mediante los Comités de Participación Ciudadana (CPC) basados en la LPC que se promulga en 2019 que deriva de la Constitución de 2017.

En términos sintéticos, puede sostenerse que los CV de 1999 contaron con fuerza legal para presionar a los gobiernos delegacionales a que atendieran las demandas ciudadanas pero centralizando la participación y la representación; los comités ciudadanos (elegidos por primera vez en 2010) fueron despojados de dicha fuerza, y su papel se concentró en torno a la organización y decisiones relacionadas con el presupuesto participativo (PP); los terceros, los CPC que fueron electos en 2019, son producto de una reglamentación que ha buscado desarticular la presencia de los grupos políticos territoriales, así como impulsar la igualdad de género. Por lo demás postula que será la Asamblea Vecinal la que tendrá la capacidad de tomar las decisiones. Hasta el momento solamente se tiene información preliminar sobre su desempeño.

\section{LA CONSTITUCIÓN DE LA CIUDAD DE MÉXICO Y LA PARTICIPACIÓN}

En cuanto a los avances jurídicos y democráticos de la Constitución, en comparación con aquellos establecidos en ordenamientos legales anteriores como la LPC, las reglas para la integración de la Asamblea Constituyente limitan la participación ciudadana y privilegian a los grupos políticos dominantes del país. La mayoría de los partidos políticos con excepción del Movimiento Regeneración Nacional (Morena), acordaron que $60 \%$ de la Asamblea fuera electa mediante el voto en las urnas; mientras que el $40 \%$ restante fuese designado por el Legislativo Federal, el Gobierno del Distrito 
Federal (ahora Ciudad de México) y la Presidencia de la República. Este acuerdo generó múltiples críticas porque la participación ciudadana fue acotada a la designación de tres quintas partes de sus integrantes. El Constituyente fue, en consecuencia, un comité integrado por los grupos en el poder lo cual garantizaba que la agenda de discusión y los resultados estuvieran circunscritos a sus intereses y preferencias legales y políticas. Algunos críticos anunciaron que esto propiciaría que la Constitución tuviera contenidos antidemocráticos o débiles (Cárdenas, 2016). Indudablemente esta integración dejó mucho qué desear, pero: ¡acotó los lineamientos jurídicos mediante los cuales los ciudadanos pueden influir en la gobernanza? Debido a que la Constitución debía ser aprobada por $66 \%$ de los constituyentes, este reparto de cuotas entre ciudadanía y partidos permitió delimitar las propuestas del PRD y, particularmente, de Morena, cuya influencia venía aumentado en la Ciudad de México a partir de las elecciones del 2015. Además, limitó las oportunidades de los ciudadanos para influir en las decisiones de la Asamblea.

La primera fase de la formulación de un "borrador" del texto constitucional también fue muy acotada. El jefe de Gobierno formó un grupo redactor integrado por 28 catedráticos, investigadores, especialistas y políticos, con perspectivas diferentes, el cual elaboró una propuesta que ya tenía un formato y límites.

Otras propuestas de la Asamblea Constituyente, como el Parlamento Abierto, la transparencia y la máxima publicidad, se quedaron en el dogma sin consecuencias efectivas en la redacción del contenido ya que no se suscitó un debate público abierto. Lo más significativo de la participación ciudadana en ese momento fue que de las 1406 iniciativas entregadas, 853 estaban elaboradas por ciudadanos u organizaciones de muy diversa índole (véase Gaceta Parlamentaria, 9 de noviembre, Anexo II). Las otras 553 fueron propuestas por los diputados constituyentes. El hecho es que la mayoría de ellas fueron desechadas sin una fundamentación pública. No obstante que 140 organizaciones integradas en el Observatorio Ciudadano para la Asamblea Constituyente solicitaron que se constituyera una Asamblea Abierta, los acuerdos del contenido de la Constitución se basaron en negociaciones entre dirigentes de los grupos partidarios.

$\mathrm{Al}$ seguir los trabajos de la Constituyente se hizo evidente que, por un lado, el PRI y el PAN se erigieron en el grupo que impuso más controversias y obstáculos y, por el otro, Morena fue otro opositor parcial. Durante las sesiones en las cuales se discutió la Constitución, las garantías propuestas fueron reiteradamente cuestionadas por los primeros dos partidos aduciendo, entre otras cosas, la carencia de presupuesto para hacerlas efectivas o la tibieza de los artículos constitucionales preliminares.

Las propuestas realizadas por el grupo redactor sobre la participación ciudadana se mantuvieron sin cambios sustanciales durante el debate legislativo y fueron acordes 
con las que integraban la LPC de 2010. Las dirigidas a disminuir los topes de requisitos que el grupo redactor propuso fueron rechazadas y se mantuvieron aquellas ya establecidas en dicha Ley. En todo caso, se incluyeron nuevos actores, como los pueblos indígenas, nuevos mecanismos de consulta y participación, así como se cambiaron algunas denominaciones, aunque ciertamente también les quitaron esa posibilidad a formas de representación formal que hasta ese momento existían, como los Consejos Delegacionales. ${ }^{3}$

\section{LOS INSTRUMENTOS DE LA PARTICIPACIÓN, LO NUEVO Y LO QUE PERDURA}

Haciendo un ejercicio comparativo entre los requisitos y actores sociales involucrados en cada una de las figuras de participación puede encontrarse lo siguiente:

\section{INICIATIVA CIUDADANA}

La LPC establecía como requisito el $0.4 \%$ de los ciudadanos inscritos en la lista nominal para realizarla. También podían convocarla el 10\% de los comités ciudadanos (en 2020 de participación comunitaria, CPC) y al menos ocho de los concejos de las Alcaldías. En el transcurso de las negociaciones se incrementó hasta el 0.25 de los ciudadanos, para disminuir en $0.13 \%$. De todas formas, el candado se estableció en que será preferente solamente si lleva el $0.25 \%$ de las firmas de los ciudadanos inscritos en la lista nominal. Disminuyó el número de actores que pueden impulsar una iniciativa ciudadana, pero se incrementó el porcentaje de ciudadanos, si se deseaba que tuviera carácter preferente (es decir, considerada por los diputados de la Ciudad de México).

\footnotetext{
${ }^{3}$ En la LPC de 2010 se constituyeron los Consejos Delegacionales, integrados por los coordinadores de cada uno de los comités ciudadanos, así como por un representante de las organizaciones ciudadanas con domicilio legal en cada delegación (ahora alcaldía). Las atribuciones de los Consejos Ciudadanos les permitían opinar sobre cuestiones como los Programas Operativos Anuales (POA) delegacionales y los informes de los jefes delegacionales. Además, podían citar a funcionarios de las delegaciones. También, la Asamblea Legislativa estaba obligada a incluir una partida económica en el presupuesto del Instituto Electoral local para el desarrollo de sus funciones (artículos del 130 al 135 de la LPC 2010). En la nueva ley desaparecen estos Consejos.
} 


\section{REFERÉNDUM}

En la LPC un diputado de la Asamblea Legislativa podía convocar a referéndum, así como el $4 \%$ de los ciudadanos y ocho Consejos Delegacionales. Conforme se desenvolvieron las negociaciones, desaparecieron propuestas como las relacionadas con los pueblos y comunidades originarias, las Alcaldías y los organismos autónomos. Finalmente queda el $0.4 \%$ de los ciudadanos inscritos en la lista nominal y dos terceras partes del Congreso de la Ciudad.

\section{Plebiscito}

En la LPC se establecía el 0.4\% de los ciudadanos, el 10\% de los comités ciudadanos y ocho consejos delegacionales. Desaparecen del proyecto los comités ciudadanos y los Consejos Delegacionales, pero se incluye al jefe de Gobierno, una tercera parte del Congreso Local, los organismos autónomos y los pueblos, comunidades indígenas y barrios originales. En algún momento regresaron los comités ciudadanos (Proyecto de Dictamen), pero en la redacción final desaparecen, así como las comunidades étnicas y los organismos autónomos. Finalmente, queda el $0.4 \%$ de los ciudadanos, el jefe de Gobierno, una tercera parte del Congreso Local y dos terceras partes de las alcaldías, imponiendo más barreras a la acción ciudadana.

\section{Consulta CIUDADANA}

En la LPC la Consulta podía realizarse a solicitud del jefe de Gobierno, los jefes delegacionales (alcaldes), las asambleas ciudadanas, comités y consejos; es la única figura donde los pueblos indígenas podían participar, en coordinación con el Consejo del Pueblo, que es la forma que adquieren los comités en las delegaciones políticas rurubanas y con pueblos originarios. El proyecto de Constitución amplia esto a solicitud de los habitantes de pueblos y colonias, mientras que el proyecto de dictamen acota la propuesta para que al menos el $1 \%$ de los ciudadanos de la lista nominal la soliciten. La Asamblea Constituyente aumentó ese requisito al 2\%, y a que se considere vinculatorio con un $15 \%$ de solicitantes, tal como quedó en la Constitución. 


\section{A. ALVARADO • H. TEJERA LA CONSTITUCIÓN DE LA CIUDAD DE MÉXICO, CIUDADANÍA Y PARTICIPACIÓN}

\section{CONSULTA POPULAR}

En el proyecto de Constitución desparecieron todas las formas que no estaban relacionadas con la consulta popular, como los recorridos del jefe delegacional, la Red de Contralorías Ciudadanas o la Colaboración Ciudadana. La figura reaparece en el Proyecto de Dictamen con un requisito del $0.4 \%$, de ciudadanos, además del jefe de Gobierno, una tercera parte de los integrantes del Congreso Local, 10\% de los comités o Asambleas y los pueblos y comunidades originarias. Finalmente queda con el $2 \%$ de la lista nominal.

\section{REVOCACIÓN DE MANDATO}

Esta figura nueva en la norma ya había sido utilizada por López Obrador cuando fue jefe de Gobierno y es una de las que presentan más "candados". En el proyecto de Constitución se requería 10\% de los ciudadanos y es vinculatorio si se revoca el mandato con la misma cantidad o más de los votos que obtuvo el representante popular. Finalmente, se considera vinculatorio si participa al menos $40 \%$ de los inscritos en la lista nominal de votantes y se alcanza $60 \%$ a favor de la revocación.

En las negociaciones sobre las figuras del plebiscito y la consulta popular, se había disminuido el porcentaje requerido para que lo solicitaran los ciudadanos. Sin embargo, los constituyentes vuelven a elevarlo, del $0.2 \%$ del padrón electoral en el borrador, retornando al 4.0 de las personas inscritas en la lista nominal. Según Mayela Delgadillo, diputada de Morena: "se ajustaron (al alza) los porcentajes para evitar un desgaste de los mecanismos por pedir un tope muy bajo de firmas". Para una comparación de las diferentes figuras de participación véase el Cuadro 1.

Además, se adiciona la propuesta de realizar consultas populares, no contenida en el documento elaborado por el grupo redactor, para efectuarse el mismo día de las elecciones y ser utilizada para temas de interés general de la Ciudad. Pero cuando se propone que se realice con el $0.4 \%$ del listado nominal, varios constituyentes aprueban subirla al $2 \%$. Otro caso donde el número de firmas para realizarse disminuye fue la iniciativa ciudadana para proponer leyes o decretos, pues el requisito de 0.25 pasa 0.13 a propuesta del Partido Acción Nacional.

Detrás de las limitaciones y obstáculos que los diputados constituyentes de todos los partidos impusieron están más de 20 años en los cuales los gobiernos han pretendido inhibir y controlar la participación. Dicha pretensión está motivada por el temor de que sea copada por la oposición o grupos adversos o ajenos al gobierno. Lo usual ha 


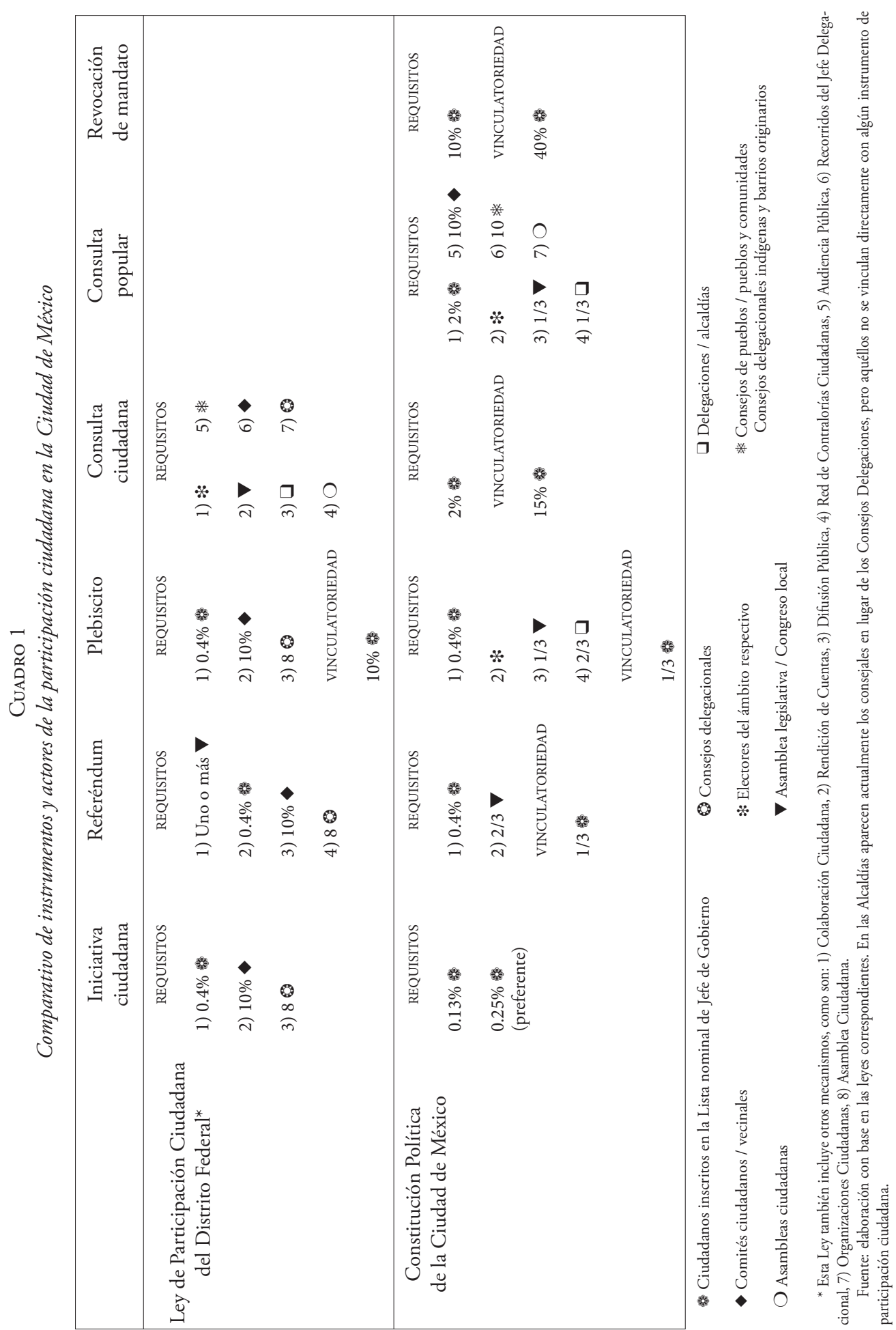


sido, entonces, despojar a la participación de su capacidad de influir en las decisiones sustantivas de los gobiernos locales, acotando la representación a las decisiones asociadas al PP y a temas insignificantes, con una agenda impuesta desde arriba. Las tasas de participación que los ciudadanos deben cubrir para ejercer determinados derechos están diseñadas para limitar la ciudadanía. Veamos el monto del PP para el 2020 será de 1420 millones de pesos que significan $3.25 \%$ del presupuesto, que aumentará paulatinamente de $3.25 \%$ en este año, hasta el $4 \%$ en 2023 . La consulta se realizó el 15 de marzo y la pandemia detuvo la aplicación del presupuesto y el seguimiento de los proyectos por parte de los denominados "comités de ejecución" vecinales.

\section{AVANCES Y RETROCESOS DE LA CONSTITUCIÓN CON RESPECTO A LA LEY DE PARTICIPACIÓN CIUDADANA}

Como era costumbre, los integrantes de la fracción partidaria de Morena en la nueva Cámara de Diputados local se resistieron a presentar una nueva propuesta de LPC durante el 2019, hasta que diversos grupos como el Frente Ciudadano Salvemos la Ciudad presentaron amparos ante el Tribunal Electoral del Poder Judicial de la Federación (TEPJF), lo cual los obligó a descongelarla. Los diputados tuvieron ocho meses para promulgarla, pero decidieron aplazarla; medida avalada con 37 votos a favor de Morena, PES y PT y 19 en contra del PRD y PAN; esta decisión parece haber estado vinculada con los intereses políticos de varios diputados con los comités ciudadanos, además se esperaba que el gobierno de la ciudad hiciera una propuesta de Ley de Participación Ciudadana.

En el momento de debatir la ley se presentaron tres propuestas, la elaborada por la Jefatura de Gobierno, así como las del PAN y el PT. No obstante que la Comisión de Participación legislativa propuso cien cambios, la ley se aprobó con modificaciones irrelevantes tanto porque se subsumieron a las propuestas del gobierno, como para cumplir los plazos establecidos por el Tribunal. ${ }^{4}$

En las formas de participación incluidas en la Constitución (catalogadas por la LPC como procedimientos de democracia directa) se reitera, con otras palabras, el contenido del articulado. Pero en cuanto a los procedimientos de Democracia Participativa, particularmente la Asamblea Ciudadana, las Comisiones de Participación Comunitaria y el PP, se modificaron varios procedimientos buscando romper con el

${ }^{4}$ [https://www.reforma.com/proponen-100-cambios-a-ley-vecinal/ar1743985?impresion=1], fecha de consulta: 13 de agosto de 2019. 
corporativismo perredista y panista de muchos comités. Es explicable. El gobierno de Morena buscó no repetir las experiencias anteriores donde muchas de las estructuras formales de representación ciudadana se convirtieron, en realidad, en cotos de poder de los partidos de oposición. Hasta ese momento, los comités ciudadanos han sido integrados, en su mayoría, por planillas acordadas con jefes delegacionales, diputados locales o funcionarios de gobierno central (antes del PRD) y por ello las designamos como elecciones gubernamentales. En las alcaldías Benito Juárez y zonas de Miguel Hidalgo, son comités controlados por el PAN (Tejera, 2015). Los cambios en la LPC generan un explicable descontento entre los integrantes de los comités ciudadanos, quienes argumentan que la nueva ley obstaculiza la participación ciudadana lograda hasta ese momento, pero no logran vetarla.

El control político de los nuevos comités (ahora Consejos de Participación Ciudadana) se matiza, por una parte, debido a que ya no se presentan planillas y, por otra, mediante la inclusión el criterio de género, lo que influye en su integración debido a que la mayoría de las unidades territoriales (UT) están integradas por un porcentaje mayor de mujeres. Algunos de los integrantes "profesionales" de los comités, que han sido elegidos reiteradamente por sus redes clientelares; es decir, lo que se ha constituido como la "representación profesional vecinal" pueden haber conservado un lugar (o varios) en las últimas elecciones, pero se entorpece la posibilidad de formar un grupo compacto como el que se lograba mediante la elección por planillas. Es difícil delinear el derrotero de estos consejos elegidos en marzo de 2020, pero la investigación etnográfica realizada antes del inicio de la pandemia, indica que fueron nuevamente integrados por quienes los consideran un espacio para su desarrollo político por medio de la intermediación; pero como fueron individuos los que se postularon, ciertamente se propició mayor diversidad en los grupos que los integran. Las discusiones al interior de los comités continúan siendo divisivas y desgastantes, y parecen haberse incrementado las dificultades para establecer acuerdos. La experiencia etnográfica muestra que es difícil que los CPC impulsen un aprendizaje ciudadano democrático. Ahora se incrementaron las posibilidades de que el consejo se diluya y sus integrantes actúen en pequeños grupos intentando representar la Unidad Territorial. Es muy probable que las divisiones y conflictos se manifiesten claramente cuando se convoque a las Asambleas Ciudadanas que deben realizarse cada tres meses (artículo 78 de la LPC). El formato de integración de los CPC no resuelve el problema estructural de acción colectiva en la CDMX, donde muchas decisiones de "mayoría" realmente benefician a grupos minoritarios y no necesariamente mejoran las condiciones de los vecinos que representan. 


\section{EL PROCESO DE ELECCIÓN DE LOS CONSEJOS DE PARTICIPACIÓN CIUDADANA YEL PRESUPUESTO PARTICIPATIVO}

Para demostrar si los cambios constitucionales propician diferencias en la dinámica de la participación ciudadana, hacemos un recuento del proceso electoral de los CPC y la selección de los proyectos asociados al PP entre 2019 y 2020.

En noviembre de 2019, ya promulgada la LPC, en una sesión extraordinaria del Consejo General del Instituto Electoral de la Ciudad de México (IECM) se aprobaron las elecciones de los CPC y la votación de proyectos del PP correspondiente a los años 2020 y 2021. Se estableció un procedimiento simultáneo para votar por medios electrónicos.

El IECM esperaba una participación de entre 4 y $9 \%$ de la lista nominal de la Ciudad de México. El 43\% de los proyectos propuestos fueron rechazados por diversas cuestiones, sobre todo factibilidad técnica o presupuestal. Lo que llama la atención es la tendencia a que dichos proyectos beneficien a grupos específicos y estén menos relacionados con el bien común. Están por ejemplo la solicitud de calentadores solares (son 1061 de 24 mil proyectos), pintura e impermeabilización (usualmente para Unidades Habitacionales).

Entre diciembre y enero se realizó el registro de propuestas y el 15 de marzo fueron las elecciones de los CPC para definir el destino de los más de 2800 millones de pesos designados para el PP de los años 2020 y 2021 (Robles, 2020). En esta consulta se probó una urna electrónica mediante tabletas digitales (Cruz, 2020).

El desarrollo de los comicios ciudadanos tropezó con complicaciones e intervenciones que cuestionan la eficacia del procedimiento formal (postulado por el IECM), y evidenció las contradicciones entre el discurso sobre la participación ciudadana y los procesos políticos. En todo caso no quedó claro si resolvía problemas como acotar al gobierno, controlar a los partidos y el otorgamiento de fondos públicos y privados que influyen en las elecciones y los votantes.

\section{EL PROCESO ELECTORAL: LA PARTICIPACIÓN CIUDADANA EN ACCIÓN}

Un mes antes de las votaciones para la integración de los CPC, y un día antes del cierre oficial de las plataformas, 60 de las 1815 unidades territoriales no habían registrado un sólo candidato; en 82 solamente se había registrado un aspirante; 33 tenían dos y en 667 había registrados entre tres y ocho candidatos de los nueve requeridos para integrar un CPC. El Consejero Electoral y presidente de la Comisión de Participación 
Ciudadana del IECM, reconoció que aun cuando el registro superaba los anteriores "la distribución de participación está totalmente desequilibrada" (Bolaños, 2020).

En cuanto a la votación por internet, el IECM reportó 3159 votos y opiniones (así se denomina a los sufragios en favor de un proyecto con presupuesto participativo), en contraste a los 10 mil ciudadanos registrados para votar por ese medio (Bolańos y Saldierna, 2020). Un análisis de las "facilidades" para votar electrónicamente destaca que los candados utilizados con el propósito de evitar fraude hicieron muy complicado el procedimiento. Una segunda razón podría ser que los líderes "corporativistas" se desanimaran al intentar manipular la elección y movilizar sus redes clientelares para que decidieran un proyecto, o votaran por ciertos candidatos, como lo hacían en otros años (Tejera, 2015).

La participación total en estas elecciones fue de 5.4\% del padrón electoral (Servín y Gómez, 2020), un punto por encima de la predicción menos optimista del IECM (de entre 4 y 9\%). Las quejas y denuncias sobre el proceso abarcaron desde fallas técnicas que obstaculizaron o impidieron el ejercicio en varias mesas de consulta, hasta los actos de violencia. En la colonia Juárez se acusó a los ambulantes de acudir coordinados a las urnas para ganar el consejo para sus líderes, como ha sido su costumbre. En Tepito se manifestaron exigiendo la anulación de las elecciones por presunta compra de voto (Servín y Gómez, 2020). En la Zona Rosa, Alcaldía de Cuauhtémoc, un grupo de aproximadamente diez personas agredió votantes y se robó el equipo y material electoral, causando el cierre temprano de la urna ubicada en Plaza del Ángel al medio día (Servín, 2020).

En las alcaldías Miguel Hidalgo y Cuauhtémoc se tuvo que recurrir a otro "protocolo especial”, según declaró el IECM, por la lentitud en el Sistema de Votación Electrónica y fallas en el equipo digital. En la colonia Cuauhtémoc, en la casilla ubicada en la calle de Río Lerma 222, tras un primer voto emitido a las 9:00 horas, el sistema falló y fue necesario esperar la llegada de boletas impresas hasta las 13:00 horas (Cruz, 2020).

Tras la jornada, el Instituto Electoral declaró el cierre imprevisto de 35 mesas de votación por "distintos motivos". Como ha sido costumbre, vecinos y candidatos expresaron su desconfianza al proceso y le solicitaran anular varios resultados presenciales, claramente sesgados, como de algunos resultados de votos emitidos mediante internet (Servín y Gómez, 2020).

La integración de los pueblos y barrios originarios de la CDMX al modelo de los CPC fue rechazada y se canceló la elección por decisión del Tribunal Electoral del Poder Judicial de la Federación (TEPJF) a petición de la Coordinadora de Pueblos y Barrios de Xochimilco, así como de la titular de la Secretaría de Pueblos y Barrios Originarios y Comunidades Indígenas Residentes. Pocos días antes de la elección, el TEPJF determinó que la figura no era adecuada desde una perspectiva intercultural, siendo 
contraproducente a los derechos de las comunidades, puesto que el CPC podría entrar en conflicto con la representación de los Consejos de Pueblos. Con ello, se suspendió la elección y la consulta del PP en pueblos pertenecientes a las alcaldías de Cuajimalpa, Magdalena Contreras, Milpa Alta, Tláhuac, Tlalpan y Xochimilco (Juárez, 2020b). El magistrado presidente de la Sala Regional, Romero Bolaños, argumentó:

No es posible armonizar ambas figuras, es necesario que el IECM se detenga y haga una revisión de la convocatoria, y por eso es por lo que se propone revocarla parcialmente en esta parte y se pueda lograr la posibilidad de que los pueblos originarios puedan participar por las vías de la participación ciudadana (Juárez, 2020b).

\section{LAS ALCALDÍAS Y LOS CONCEJALES: NUEVAS INSTITUCIONES Y VIEJAS PRÁCTICAS}

El paso de delegaciones a alcaldías pretende generar una estructura de gobierno colegiada en las demarcaciones políticas de la Ciudad de México. Para ello, en la Constitución se establece que a la candidatura de alcaldes se integra una planilla de seis candidatos a concejales (el 60\% de los que componen el Concejo) que, por ello, serán electos de manera simultánea. El 40\% restante serán escogidos a través del procedimiento de representación proporcional (artículo Vigésimo Segundo). En la siguiente elección esto podrá modificarse hasta quince concejales dependiendo del número de habitantes por demarcación. Del trabajo etnográfico realizado en el contexto de las campañas electorales de 2018 en la Ciudad de México y la observación realizada el día de los comicios (Tejera, 2019a; 2019b), esta peculiaridad estuvo poco clara entre los votantes. Los candidatos a concejales no necesitaron hacer algún tipo de campaña y, ciertamente, algunos de ellos aceptaron la integración a la planilla con la expectativa de "encontrar trabajo en la Alcaldía" como afirmaba uno de los aspirantes entrevistados.

Los candidatos a alcaldes muy rara vez mencionaron la existencia de los candidatos a concejales por temor a que esto confundiera más a los vecinos de lo que ya estaban por las coaliciones particulares que contendieron en esas elecciones, especialmente la del PRD con el PAN. En el caso de los candidatos de Morena/PES, como la estrategia era apoyarse en la candidatura de López Obrador, el tema desapareció de las campañas.

Una vez instaladas las administraciones, en varias de éstas los concejales son invisibles. Aunque su salario es garantizado por la jefa de Gobierno a partir de finales de 2018 y en 2020 tienen un sueldo homologado al de subdirector "A" equivalente a 35 mil pesos mensuales, en algunas delegaciones como Cuajimalpa se llegó a deber a la estructura asociada al Concejo hasta 6 meses de pagos. En Tlalpan se quejan de que "sus oficinas eran muy pequeñas" y la alcaldesa responde que en los reclamos "hay intereses 
políticos", porque quienes lo hacen son de oposición (los panistas deciden no ocupar sus oficinas). Como afirmaba en una reunión de 105 concejales (de los 160 existentes) el alcalde de Cuauhtémoc (en la cual los panistas abandonan la sesión porque se presenta a ella): "hoy por hoy, los concejales no existen en la Constitución más que para ser votados el día de la jornada electoral, pero no existen dentro del funcionamiento administrativo de gobierno de las alcaldías de manera individual. Existe el Concejo, pero los concejales no" (Sánchez, 2019:5). Además, desde enero de 2019 los diputados locales de Morena pretenden acotar la intervención de los concejales en la definición del presupuesto, requisito establecido en la Constitución, al intentar modificar la ley de alcaldías para que el alcalde lo envíe independientemente de que haya o no consenso.

A un año de comenzar las alcaldías, en la mayoría la relación entre el Concejo y el alcalde se circunscribe a los seis concejales que lo acompañaron en su planilla. Aun con los nuevos reglamentos los concejales se han desvanecido de la esfera pública.

\section{A MANERA DE CONCLUSIÓN}

LA NUEVA INSTITUCIONALIDAD DE LOS GOBIERNOS LOCALES

Y LAS LIMITACIONES AL EERCICIO DE CIUDADANÍA PLENA

Las modificaciones constitucionales a la participación ciudadana sancionan y ratifican la gran mayoría de figuras que ya existían, y sólo incluyen algunos nuevos actores, procedimientos e instituciones. Como novedad está la inclusión de los pueblos indígenas y nuevas figuras como la revocación de mandato y los concejales, pero hasta el momento no parecen significar transformaciones sustantivas en la gobernanza que ya existía. La respuesta sobre si la LPC significó una mejoría en los procesos participativos, implica aspectos particulares difíciles de contestar debido a que a la elección de los CPC siguió la pandemia de Covid19, y hasta ahora las irregularidades persistentes no han sido resueltas con nuevas reglas.

En términos de los avances jurídicos, al compararlos con ordenamientos anteriores, la Constitución y la LPC reeditan los comités por unidades territoriales. Aun cuando avanza en la pretensión de que no sean copados por grupos particulares, continúa despojándolos de atribuciones que les permitan influir efectivamente en las políticas públicas, conforme al articulo 25 constitucional, inciso A, numeral 2, que a la letra dice:

Las autoridades de la Ciudad garantizarán la democracia participativa, entendida como el derecho de las personas a incidir, individual o colectivamente, en las decisiones públicas y en la formulación, ejecución, evaluación y control del ejercicio de la función pública, en los términos que las leyes señalen. 
La LPC carece de mecanismos o procedimientos mediante los cuales se propicie la representación vecinal y su participación en las decisiones a nivel de alcaldías. Debe reformarse para que los ciudadanos puedan influir en el diseño de las decisiones públicas, haciéndose explícita su capacidad representativa de las demandas vecinales.

Hemos visto que las formas de participación vecinal propuestas en la Constitución y la nueva LPC mantienen los problemas de representación entre vecinos; así como las tensiones para la construcción de mayorías y de consensos. Pero además no resuelven otros temas, como la necesidad de crear una "unidad" de representación básica que permita que las comisiones trabajen mejor. En algunos casos las manzanas no representan a los vecinos y las colonias son efectivamente heterogéneas; en otros, las unidades territoriales cortan grupos que tienden a trabajar unidos. Entonces ¿̨cuál sería la unidad de representación óptima? Lo que podemos decir es que la LPC, la Constitución y todo lo que se ha trabajado en esta materia no logra un acuerdo de cuáles son las unidades más representativas de una "comunidad urbana" ideal para este caso. Se requiere modificar las dimensiones del territorio que representan los CPC debido a que su extensión debilita la representación y obstaculiza la participación. Reducir la escala de representación permitiría abordar los problemas más cercanos a los vecinos con soluciones con impacto local.

En cuanto al alcance de la nueva reglamentación para transformar las delegaciones en alcaldías y su contribución a la gobernanza; es difícil sostener que se ha producido una transformación en las formas de ejercicio de gobierno en las demarcaciones políticas. Las prácticas de los alcaldes se caracterizan por desplazar a los concejales incómodos y sólo trabajan con aquellos que formaban la planilla con la cual ganaron. En diversas alcaldías los concejales siguen siendo líderes de organizaciones clientelares que encontraron ahora un empleo bien remunerado. Los concejales incómodos llevaron a la coalición de Morena a buscar modificaciones a la ley de alcaldías, para evitar que sea obligatorio que los presupuestos anuales requieran ser aprobados por consenso. Los alcaldes también han solicitado a los diputados que reduzcan sus atribuciones. En este sentido las alcaldías no resuelven problemas de representación ni decisión básicos. Los Concejos implican para la mayoría de los alcaldes, una "piedra en el zapato" que dificulta sus decisiones administrativas y presupuestales. Más allá del imaginario deliberativo mostrado por los constituyentes, lo cierto es que bajo las condiciones políticas actuales hay mínima representatividad y las decisiones se toman a partir de un formato personalista y excluyente. En el trabajo etnográfico encontramos que los concejales pertenecientes a los partidos de oposición se quejan de haber sido excluidos del gobierno de la delegación, pero también carecen de representatividad política territorial (fueron elegidos por el método representación proporcional) lo que incrementa su debilidad para influir en las decisiones. 
Con base en lo anterior puede concluirse que la nueva normatividad tampoco resuelve algunos problemas de la acción gubernamental; los nuevos instrumentos no solucionan los conflictos urbanos antiguos, como los creados por las acciones vecinales o por actores privados, como los desarrolladores de megaproyectos. Mantiene un formato de participación ciudadana limitado que no permite a los ciudadanos influir realmente en las decisiones de la entidad. Además, ha permitido la preservación de mecanismos clientelares. Finalmente, establece nuevas reivindicaciones sin las condiciones que puedan sustentarla (como el Fondo de Capitalidad). En este sentido, no contribuye a resolver los problemas de gobernanza ni de representación democrática metropolitanos.

Las nuevas reglas permiten que actores de las esferas dominantes y privilegiadas de la ciudad influyan y sigan utilizando la ciudad para su beneficio excluyente. Limita las voces de grupos minoritarios y locales. Esto converge con un gobierno formalmente de izquierda que acepta y promueve políticas neoliberales y reglas que inhiben, limitan, fragmentan o pulverizan las acciones colectivas. Por lo tanto, sería de esperarse que continúen las movilizaciones, las protestas y algunas transgresiones (protestas dirigidas a tomar edificios o realizar bloqueos contra proyectos) sin mecanismos reglamentarios para canalizarlas, más allá de la fastuosa Constitución.

\section{REFERENCIAS}

Alvarado, Arturo (2012). El tamaño del infierno. México, El Colegio de México.

— (2018). "La ilusión de la seguridad, el crimen y las expectativas de gobernanza: una megalópolis", en Patrick Le Galès y Vicente Ugalde (eds.), Ciudad de México. Lo que se gobierna y lo que no se gobierna en una gran metrópoli. México: El Colegio de México.

Álvarez, Lucia (1997). Participación y democracia en la Ciudad de México. México: La Jornada Ediciones/Centro de Investigaciones Interdisciplinarias en Ciencias y Humanidades-UNAM. Azuela, Antonio et al. (2019). Ciudad de México. Inercias urbanisticas y proceso constitucional. México, Centro de Investigación y Docencia Económicas.

Bolaños, Ángel (2019). "Aprueba el IECM la convocatoria de la elección de Copacos", La Jornada, México, 16 de noviembre.

_ (2020a). "Colonias residenciales, sin interés en representación ciudadana: IECM", La Jornada, México, 15 de febrero [https://www.jornada.com.mx/ultimas/capital/2020/02/15/ colonias-residenciales-sin-interes-en-representacion-ciudadana-9974.html].

(2020b). "Con marchas, pueblos de Xochimilco exigen elección de comisiones", La Jornada, México, 11 de marzo [https://www.jornada.com.mx/ultimas/capital/2020/03/11/conmarchas-pueblos-de-xochimilco-exigen-eleccion-de-comisiones-8617.html]. 


\section{A. ALVARADO • H. TEJERA LA CONSTITUCIÓN DE LA CIUDAD DE MÉXICO, CIUDADANÍA Y PARTICIPACIÓN}

Bolaños, Ángel y Georgina Saldierna (2020). "Escasa participación ciudadana en la red para elegir a las Copacos", La Jornada, México, 14 de marzo.

Cárdenas, Jaime (2016). "La tibia nueva Constitución de la Ciudad de México", El Cotidiano, núm. 203, México, División de Ciencias Sociales y Humanidades, UAM-Azcapotzalco, pp. 63-74.

Cruz, Héctor (2020a). "Pese a medidas por coronavirus, realizan elecciones de presupuesto participativo”, El Universal, México, 15 de marzo.

- (2020b). "Acusan retrasos y fallas en tabletas en consulta ciudadana”, El Universal, México, 16 de marzo.

Cunill, Nuria (1997). Repensando lo público a través de la sociedad. Nuevas formas de gestión pública y representación social. Venezuela: Centro Latinoamericano de Administración para el Desarrollo.

Díaz, Ana y Dionisio Zabaleta (2018). "La Ciudad de México: un modelo de gobernanza fragmentado, ¿divide y gobernarás?”, en Patrick Le Galès y Vicente Ugalde (eds.), Ciudad de México. Lo que se gobierna y lo que no se gobierna en una gran metrópoli. México: El Colegio de México.

Foucault, Michel (1991). “Governmentality”, en Graham Burchell, Colin Gordon y Peter Miller (eds.), The Foucault effect: studies in Governmentality. Chicago: University of Chicago Press.

Hernández, Eduardo (2020). “TEPJF pospone consulta en 48 pueblos y comunidades”, El Universal, México, 14 de marzo.

Juárez, Víctor (2019). "Aprueban consulta de Presupuesto 20-21", Reforma, México, 16 de noviembre.

- (2020a). "Frena TEPJF Copacos en pueblos", Reforma, México, 5 de marzo.

- (2020b). "Cancela IECM consulta en 48 pueblo", Reforma, México, 6 de marzo.

Le Galès, Patrick y Vicente Ugalde (eds.), Ciudad de México. Lo que se gobierna y lo que no se gobierna en una gran metrópoli. México: El Colegio de México.

León, Ulises (2020). "Celebran anulación de consulta", Reforma, México, 7 de marzo [https:// argumentos.xoc.uam.mx/index.php/argumentos/article/view/1055/1025].

Marván, Ignacio (2012). “De la ciudad del presente al gobierno propio, 1970- 2000”, en Ariel Rodríguez (coord.), Historia política de la Ciudad de México: desde su fundación hasta el año 2000. México: El Colegio de México.

Murray, Li Tania (2007). "Governmentality", Anthropologica, Canadian Anthropology Society, núm. 2, vol. 49, pp. 275-281.

Orstrom, Elinor (2005). Understanding the Diversity of Structured Human Interactions. Princeton: Princeton University Press.

Robles, Johana (2020). “Capitalinos decidirán gasto de 2 mil 800 mdp”, El Universal, México, 14 de marzo [https://www.eluniversal.com.mx/metropoli/cdmx/capitalinos-decidiran-gasto-de-2mil-800-mdp].

Sánchez Mejorada, Cristina (2000). "La participación ciudadana en el Distrito Federal. Reflexiones sobre la Ley y las elecciones vecinales”. El Cotidiano, núm. 99, vol. 16, enero-febrero, México, División de Ciencias Sociales y Humanidades, UAM-Azcapotzalco, pp. 80-91. 
Sánchez, Ingrid (2019) "Quieren los concejales ejercer contrapeso", Reforma, Ciudad, México, 6 de septiembre.

Servín, Mirna (2020). "Suspenden votación comunitaria en casilla de la Zona Rosa por violencia”, La Jornada, México, 15 de marzo.

Servín, Mirna y Laura Gómez (2020a). "Plagada de anomalías, elección de comisiones de participación”, La Jornada, México, 16 de marzo.

- (2020b). "En elección y consulta del domingo participó 5.3\% del padrón: IECM", La Jornada, México, 17 de marzo.

Tejera Gaona, Héctor (2015). Estructura politica y participación ciudadana en la Ciudad de México. México: UAM/Gedisa.

_ (2019a). "Coaliciones políticas y comportamiento electoral en la Ciudad de México: las elecciones de 2018”, Alteridades, núm. 57, vol. 29, México, Departamento de Antropología, UAM Iztapalapa, pp. 9-22.

- (2019b). "Coaliciones políticas, proselitismo electoral y percepciones ciudadanas sobre la democracia: deterioro democrático en los procesos electorales de 2018 en la Ciudad de México", en Diana Guillén, Alejandro Monsiváis y Héctor Tejera Gaona (coords.), México 2012-2018 ¿Erosión de la Democracia?, México: UAM/Instituto de Investigaciones Dr. José María Luis Mora/Juan Pablos Editor.

Tejera Gaona, Héctor y Pablo Castro (2010). Participación y ciudadanía en la Ciudad de México. México: UAM/Juan Pablos Editor.

Tejera Gaona, Héctor, Pablo Castro y Emanuel Hernández (coords.) (2014). Continuidades, rupturas y regresiones. Contradicciones y paradojas de la democracia mexicana. México: UAMIztapalapa.

Ward, Peter (2004). México una megaciudad: desarrollo y política, 1970-2002. México: Porrúa/ El Colegio Mexiquense.

Yankelevich, Javier (2018). Antropología del poder constituyente de la Ciudad de México. México, Suprema Corte de Justicia de la Nación.

Zermeño, Sergio, Saúl Gutiérrez y Ernesto López (2002). "La democracia impertinente: Comités Vecinales en una cultura estatal”, Revista Mexicana de Sociología, núm. 1, vol. 64, México, Instituto de Investigaciones Sociales, Universidad Nacional Autónoma de México, pp. 231-268.

Ziccardi, Alicia (1998). Gobernabilidad y participación ciudadana en la ciudad capital. México: Instituto de Investigaciones Sociales, Universidad Nacional Autónoma de México/Miguel Ángel Porrúa.

(2004). Participación ciudadana y politicas sociales del ámbito local. México: Instituto de Investigaciones Sociales, Universidad Nacional Autónoma de México/ Instituto Nacional de Desarrollo Social/Consejo Mexicano De Ciencias Sociales. 



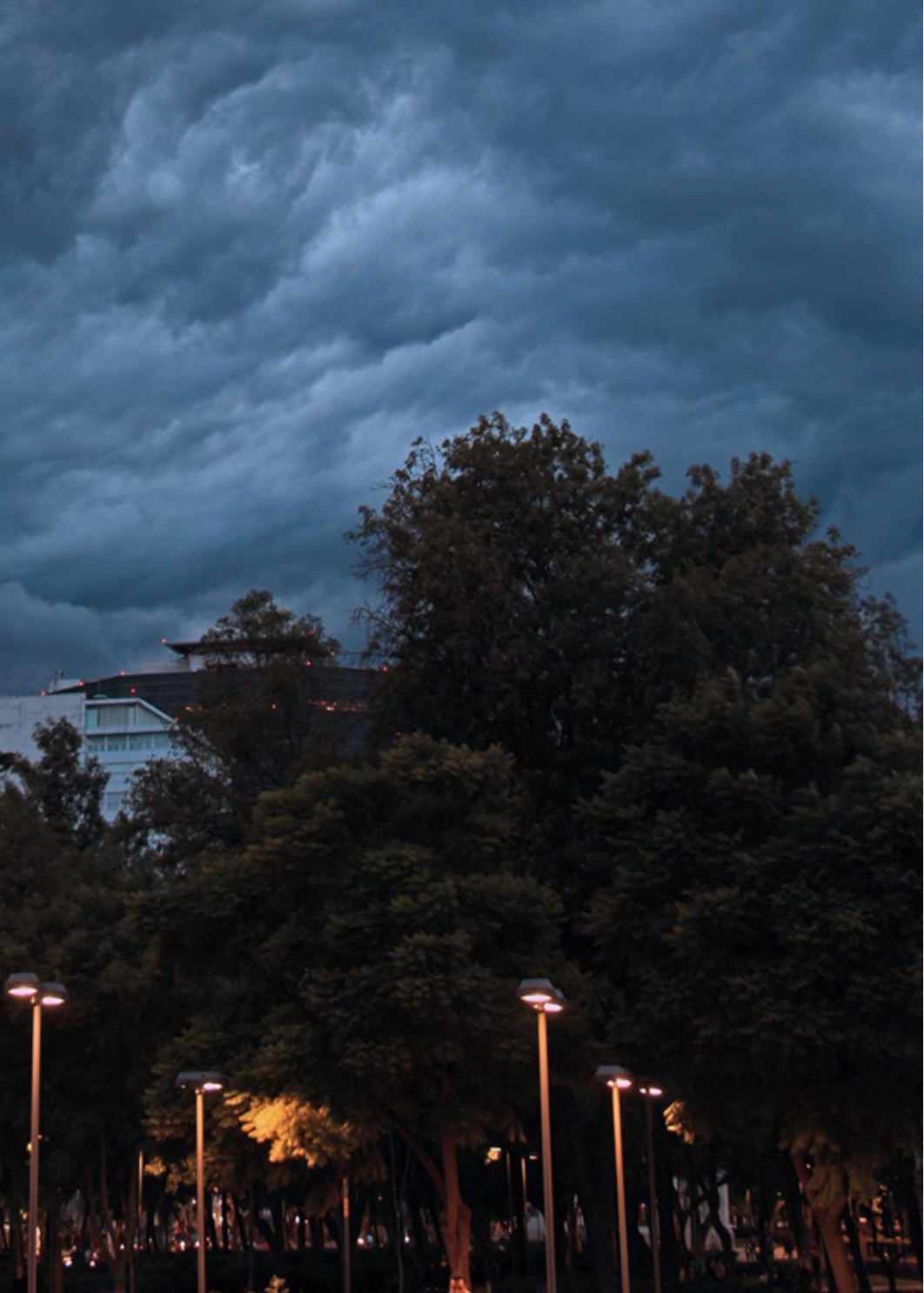


Fotografía | Iraís Hernández Güereca 